\title{
Escherichia coli Vertebral Osteomyelitis Diagnosed According to Broad-range 16S rRNA Gene Polymerase Chain Reaction (PCR)
}

\author{
Satoshi Shibata ${ }^{1}$, Ryutaro Tanizaki ${ }^{1}$, Koji Watanabe ${ }^{1}$, Kenta Makabe ${ }^{2}$, Naoki Shoda ${ }^{2}$, \\ Satoshi Kutsuna ${ }^{3}$, Maki Nagamatsu ${ }^{4}$, Shinichi $\mathrm{Oka}^{1}$ and Norio Ohmagari ${ }^{3}$
}

\begin{abstract}
Identifying the causative agent of pyogenic osteomyelitis is often challenging, especially when antibiotics are administered before a biopsy. We herein present a case of osteomyelitis in the cervical vertebrae presenting with progressive paralytic symptoms, in which we successfully identified Escherichia coli from a biopsy specimen using broad-range 16S rRNA gene polymerase chain reaction (PCR) even though sensitive antibiotics had been used for more than 50 days before the biopsy. Broad-range 16S rRNA gene PCR is a useful diagnostic method, especially when prebiopsy antibiotics are unavoidably used for a clinically unstable state.
\end{abstract}

Key words: a broad-range $16 \mathrm{~S}$ rRNA gene PCR, Escherichia coli (E. coli), vertebral osteomyelitis, prebiopsy antibiotics exposure

(Intern Med 54: 3237-3240, 2015)

(DOI: 10.2169/internalmedicine.54.5066)

\section{Introduction}

Identifying the causative agent of pyogenic osteomyelitis is often challenging, especially when antibiotics are administered before performing a biopsy of the involved lesion. We experienced the case of a patient presenting with complete paraplegia resulting from osteomyelitis of the cervical vertebrae in which Escherichia coli (E. coli) was identified as a causative pathogen based on broad-range $16 \mathrm{~S}$ ribosomal RNA (rRNA) gene polymerase chain reaction (PCR) followed by detected sequencing (broad-range 16S rRNA gene PCR).

\section{Case Report}

A 58-year-old woman was referred to our hospital with a 1-month history of cervical back pain, fever, progressive symmetric weakness of both limbs and bladder and rectal disturbance (BRD) (day 0). More than two months before referral (day -82), she developed bacteremia caused by $E$. coli resulting from a urinary tract infection and was treated with cefmetazole (CMZ) for 17 days at a local hospital. The E. coli, which was isolated from blood and urine cultures, was susceptible to ampicillin/sulbactam, cefazolin, CMZ, ceftazidime, meropenem and amikacin and resistant to piperacillin and levofloxacin. Thereafter, the fever and pyuria reappeared, and bilateral renal abscesses were identified on magnetic resonance imaging (MRI) (day -52). Antibiotic treatment (intravenous or oral cephalosporin) was administered intermittently depending on the patient's symptoms, such as fever and pyuria (Fig. 1). During this period, she developed progressive cervical back pain, followed by symmetric weakness of both limbs and BRD. MRI of the cervical spine was performed on day -33, which showed osteomyelitis accompanied with discitis of C5 and C6 surrounded by an epidural abscess compressing the spinal cord (Fig. 2). She was transferred to our hospital for surgical procedures (day 0). On admission, she showed complete paraplegia of both legs without a fever. She had no past history other than

\footnotetext{
${ }^{1}$ AIDS Clinical Center, National Center for Global Health and Medicine, Japan, ${ }^{2}$ Department of Orthopedic Surgery, National Center for Global Health and Medicine, Japan, ${ }^{3}$ Disease Control and Prevention Center, National Center for Global Health and Medicine, Japan and ${ }^{4}$ Department of Infectious Disease, Research Institute, National Center for Global Health and Medicine, Japan

Received for publication January 30, 2015; Accepted for publication April 13, 2015

Correspondence to Dr. Satoshi Shibata, flush-ss@ hotmail.co.jp
} 


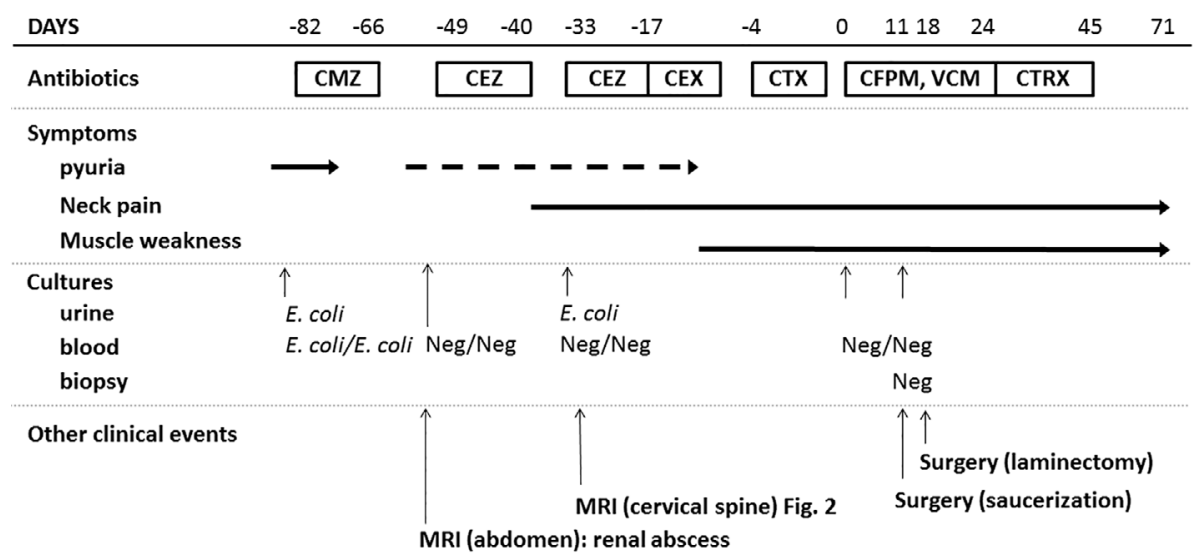

Figure 1. Clinical course of the present case. The date of referral to our hospital is fixed as day 0. CMZ: cefmetazole, CEZ: cefazolin, CEX: cephalexin, CTX: cefotaxime, CFPM: cefepime, VCM: vancomycin, CTRX: ceftriaxone, neg: negative

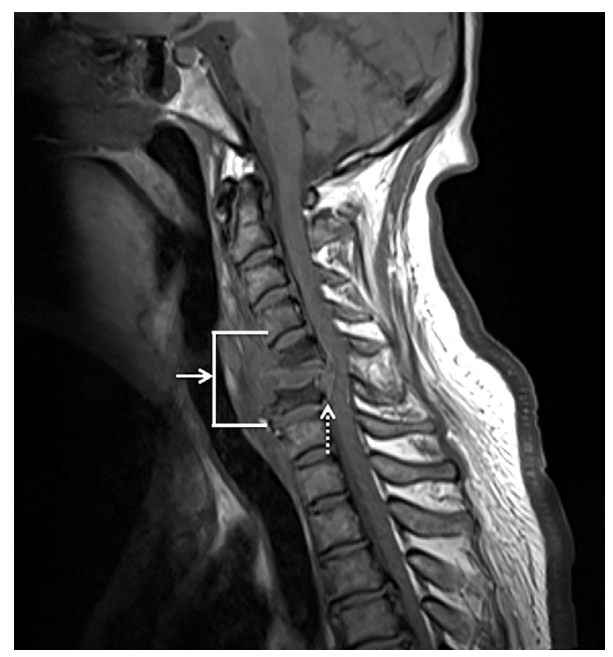

Figure 2. MRI of the cervical spine. Osteomyelitis accompanied with discitis between the $\mathrm{C} 5$ and $\mathrm{C} 6$ cervical vertebrae (dashed arrow) was surrounded by an epidural abscess compressing the spinal cord (solid arrow).

diabetes mellitus type 2 without medication. Treatment with intravenous cefepime (CFPM: 2 g every $8 \mathrm{~h}$ ) and vancomycin (VCM: $1 \mathrm{~g}$ every $12 \mathrm{~h}$ ) was started as an empiric therapy. Blood cultures performed at referral were negative. Saucerization of infected bone with bone grafting on day 11, laminectomy of C5-C6 and drainage of the spinal epidural abscess were performed on day 18. No visible organisms were identified on a Gram-stained smear of the abscess material, although it showed a considerable number of polymorphonuclear leukocytes. Cultures of the abscess and soft tissue were also negative. Therefore, we performed molecular identification with PCR amplification and a sequence analysis of the $16 \mathrm{~S}$ rRNA gene. Bacterial DNA was extracted from homogenized biopsy samples (abscess and soft tissue) using the DNA extraction kit according to the manufacturer's instructions (MORA-EXTRACT, Kyokuto Pharmaceutical Industrial, Tokyo, Japan). The 16S rRNA gene was amplified using the PCR primers; 5'-TTGGAGAGTTT GATCCTGGCTC-3' and 5' -ACGGGCGGTGTGTRC$3^{\prime}(1,2)$. Thereafter, the purified PCR products were sequenced with Big Dye terminator reagents on an ABI 3130XL genetic analyzer (Applied Biosystems, Carlsbad, USA). We performed a homologous comparison using a GenBank BLAST search and the EzTaxon server (http://ww w.ezbiocloud.net/eztaxon) phylogenetic tools. Sequences of the 16S rRNA gene amplified from the abscess and soft tissue showed $99.92 \%$ identity $(1,267$ bp over the entire 1,269 bp fragment) and $100 \%$ identity $(1,144 \mathrm{bp}$ over the entire 1,144-bp fragment) to that of E. coli (KCTC $2441 \mathrm{~T}$; accession number EU014689). Based on these results, we determined the isolates to be $E$. coli. Nucleotide sequences of the abscess and soft tissue have been deposited in DDBJ under accession numbers LC037388 and LC037389.

Referring to the susceptibility of the $E$. coli cultured from urine and blood obtained at the former hospital, CFPM and VCM were switched to ceftriaxone (CTRX) (2 g q12 h) on day 24. The patient completed a 6-week course of intravenous antibiotic treatment, although she developed Clostridium difficile colitis and was treated with oral VCM during the therapy. She remained clinically stable, and abscess volume reduction was confirmed on MRI on day 68, although the paraplegia in both legs and BRD remained.

\section{Discussion}

Identifying the causative pathogen of pyogenic vertebral osteomyelitis is important for the optimal use of antibiotics. However, blood cultures often show negative results due to their low sensitivity (range across studies, 30 to $78 \%$ ) (3). Cultures of biopsy specimens, obtained via CT-guided or surgical techniques, have great diagnostic value, as their sensitivity is generally higher than that of blood cultures (ranging from 47 to 100\%) (3). Prebiopsy antibiotic exposure may enhance the false negative rate of cultures. Several studies have shown that the diagnostic yield of cultures of 
Table. Clinical Summary of Cases with Osteomyelitis Microbiologically Diagnosed with 16S rRNA.

\begin{tabular}{|c|c|c|c|c|c|}
\hline Reference & Clinical diagnosis & $\begin{array}{l}\text { Number of cases } \\
\text { (prior antibiotic } \\
\text { treatment) }\end{array}$ & $\begin{array}{l}\text { Duration of prior } \\
\text { antibiotics }\end{array}$ & $\begin{array}{l}\text { PCR positive / Culture } \\
\text { positive }\end{array}$ & Organism \\
\hline 17 & vertebral osteomyelitis & $45(29)$ & 11.0 days $[1-115$ days $]$ & $\begin{array}{l}24 \text { cases }(53.3 \%) / 13 \text { cases } \\
(28.9 \%)\end{array}$ & $\begin{array}{l}\text { S. aureus } 9 \text { cases, S. epidermidis } 3 \text { cases, E. } \\
\text { coli } 2 \text { cases, S. agalactiae } 2 \text { cases, others } 8 \\
\text { cases, negative } 21 \text { cases }\end{array}$ \\
\hline 18 & bone or joint infection & 525 (na) & - & $\begin{array}{l}112 \text { cases }(21.3 \%) / 105 \\
\text { cases }(20 \%)\end{array}$ & $\begin{array}{l}\text { Staphylococci } 53 \text { cases, Streptococci } 11 \text { cases, } \\
\text { enterobacteriae } 11 \text { cases, HACEK } 3 \text { cases, } \\
\text { others } 3 \text { cases (only conguent results } \\
\text { between culture and PCR) }\end{array}$ \\
\hline 19 & spinal infection & 18 & 2 days & $\begin{array}{l}11 \text { cases }(61.1 \%) / 9 \text { cases } \\
(50.0 \%)\end{array}$ & $\begin{array}{l}\text { S. aureus } 7 \text { cases, S. epidermidis } 1 \text { case, } \\
\text { Streptococcus } 2 \text { cases, }\end{array}$ \\
\hline 20 & spondylodiscitis & $19(0)$ & - & $19(100 \%) / 14(73.7 \%)$ & $\begin{array}{l}\text { Staphylococci } 12 \text { cases, Streptococci } 2 \text { cases, } \\
\text { Actinomyces israelii } 2 \text { cases, others } 3 \text { cases }\end{array}$ \\
\hline 21 & arthritis with osteomyelitis & $1(1)$ & 14 days & positive / negative & Streptococcus Pyogenes \\
\hline 23 & osteomyelitis & $1(0)$ & $\begin{array}{l}\text { (antibiotic treatment } \\
\text { was discontinued } 6 \\
\text { months before biopsy) }\end{array}$ & positive / negative & Helicobacter rappini \\
\hline 24 & osteomyelitis & $1(0)$ & - & positive / negative & Mycoplasma pneumoniae \\
\hline 25 & osteomyelitis of the patella & $1(1)$ & - & $\begin{array}{l}\text { positive / negative in } \\
\text { normal procedure, BCYE } \\
\text { was positive }\end{array}$ & Legionella anisa \\
\hline
\end{tabular}

biopsy specimens is diminished by antecedent antibiotic use (4-6). The discontinuation of antibiotics at least 48 hours prior to biopsies is generally recommended if the patient's condition is clinically stable (7). E. coli is the second most frequent causative agent of vertebral osteomyelitis, which is typically present after urinary tract infections (7). Hence, in most cases of osteomyelitis caused by this pathogen, antibiotics have already been administered when symptoms of vertebral osteomyelitis emerge (8). The present patient showed progressive paralytic symptoms at referral, despite the use of cefotaxime (CTX). In view of the fact that E. coli was cultured from both urine and blood at the former hospital, E. coli was the most highly suspected pathogen. However, 40 days had already passed at the time at which she developed cervical back pain since the onset of E. coli bacteremia. Other pathogens causing catheter-related infections should have been considered as causative agents because she was being treated with a peripheral intravenous line at that time. For these reasons, we were unable to discontinue the antibiotics before the biopsy, and identifying the causative agent is absolutely imperative for the optimal use of antibiotics. We continued antibiotics with VCM in addition to CFPM as an empiric therapy at referral, which resulted in negative results on the Gram-stained smear and culture of the biopsy specimen. We subsequently performed broad-range 16S rRNA gene PCR using a biopsy specimen to identify the causative agent. Several previous studies have demonstrated the usefulness of broad-range 16S rRNA gene PCR for obtaining the diagnosis of normally aseptic organ infections, such as endocarditis, arthritis and vertebral osteomyelitis (9-15), although culture methods remain a reliable standard method for diagnosing infectious diseases (7). Moreover, the high priority of broad-range 16S rRNA gene
PCR is indicated by the false-negative results in culture due to preceding antibiotic treatment before the biopsy (16). Table shows a clinical summary of cases of osteomyelitis diagnosed with broad-range $16 \mathrm{~S}$ rRNA gene PCR. PCR generally has higher sensitivity than cultures, even in cases involving exposure to antibiotics prior to biopsy (17-25). In the current case, surprisingly, broad-range 16S rRNA gene PCR amplified E. coli-specific DNA from the biopsy specimen despite the preceding administration of susceptible antibiotics for more than approximately 50 days. Moreover, the negative results for other pathogens on "broad-range" $16 \mathrm{~S}$ rRNA gene PCR made it possible to differentiate other potential pathogens. These results emphasize the utility of broad-range $16 \mathrm{~S}$ rRNA gene PCR in difficult clinical settings.

On the other hand, this method has some limitations, such as difficulty in differentiating the causative agent of infection from colonization with environmental bacteria. Moreover, the interpretation of broad-range $16 \mathrm{~S}$ rRNA is dependent on the results of a similarity search of the sequence database, which cannot be accurately identified with phenotypic tests in microbiology laboratories. More detailed guidelines for the interpretation of sequence data are expected for the more wide use of this method in the clinical setting.

In conclusion, broad-range $16 \mathrm{~S}$ rRNA gene PCR is a useful diagnostic method, especially when prebiopsy antibiotics are unavoidably used for a clinically unstable state. Further clinical evidence of the sensitivity and specificity of broadrange 16S rRNA gene PCR in the clinical setting is warranted.

The authors state that they have no Conflict of Interest (COI). 


\section{Financial Support}

This work was supported by a grant from the National Center for Global Health and Medicine (25-114).

\section{References}

1. Simmon KE, Croft AC, Petti CA. Application of SmartGene IDNS software to partial $16 \mathrm{~S}$ rRNA gene sequences for a diverse group of bacteria in a clinical laboratory. J Clin Microbiol 44: 44004406, 2006.

2. Masaki T, Ohkusu K, Hata H, et al. Mycobacterium kumamotonense Sp. Nov. recovered from clinical specimen and the first isolation report of Mycobacterium arupense in Japan: Novel slowly growing, nonchromogenic clinical isolates related to Mycobacterium terrae complex. Microbiol Immunol 50: 889-897, 2006.

3. Mylona E, Samarkos M, Kakalou E, Fanourgiakins P, Skoutelis A. Pyogenic vertebral osteomyelitis: a systematic review of clinical characteristics. Semin Arthritis Rheum 39: 10-17, 2009.

4. de Lucas EM, Gonzalez Mandly A, Gutierrez A, et al. CT-guided fine-needle aspiration in vertebral osteomyelitis: true usefulness of a common practice. Clin Rheumatol 28: 315-320, 2009.

5. Rankine JJ, Barron DA, Robinson P, Millner PA, Dickson RA. Therapeutic impact of percutaneous spinal biopsy in spinal infection. Postgrad Med J 80: 607-609, 2004.

6. Hassoun A, Taur Y, Singer C. Evaluation of thin needle aspiration biopsy in the diagnosis and management of vertebral osteomyelitis (VO). Int J Infect Dis 10: 486-487, 2006.

7. Zimmerli W. Clinical practice. Vertebral osteomyelitis. N Engl J Med 362: 1022-1029, 2010.

8. Kem RZ, Houpt JB. Pyogenic vertebral osteomyelitis: diagnosis and management. Can Med Assoc J 130: 1025-1028, 1984.

9. Bosshard PP, Kronenberg A, Zbinden R, Ruef C, Böttger EC, Altwegg M. Etiologic diagnosis of infective endocarditis by broad-range polymerase chain reaction: a 3-year experience. Clin Infect Dis 37: 167-172, 2003.

10. Welinder-Olsson C, Dotevall L, Hoqevik H, et al. Comparison of broad-range bacterial PCR and culture of cerebrospinal fluid for diagnosis of community-acquired bacterial meningitis. Clin Microbiol Infect 13: 879-886, 2007.

11. Yang $S$, Ramachandran $P$, Hardick A, et al. Rapid PCR-based diagnosis of septic arthritis by early Gram-type classification and pathogen identification. J Clin Microbiol 46: 1386-1390, 2008.

12. Fenollar F, Roux V, Stein A, Drancourt M, Raoult D. Analysis of 525 samples to determine the usefulness of PCR amplification and sequencing of the $16 \mathrm{~S}$ rRNA gene for diagnosis of bone and joint infections. J Clin Microbiol 44: 1018-1028, 2006.
13. Fihman V, Hannouche D, Bousson V, et al. Improved diagnosis specificity in bone and joint infections using molecular techniques. J Infect 55: 510-517, 2007.

14. Fuursted K, Arpi M, Lindblad BE, Pedersen LN. Broad-range PCR as a supplement to culture for detection of bacterial pathogens in patients with a clinically diagnosed spinal infection. Scand J Infect Dis 40: 772-777, 2008.

15. Lecouvet F, Irenge L, Vandercam B, Nzeusseu A, Hamels S, Gala JL. The etiologic diagnosis of infectious discitis is improved by amplification-based DNA analysis. Arthritis Rheum 50: 29852994, 2004.

16. Rampini SK, Bloemberg GV, Keller PM, et al. Broad-range 16S rRNA gene polymerase chain reaction for diagnosis of culturenegative bacterial infections. Clin Infect Dis 53: 1245-1251, 2011.

17. Choi SH, Sung H, Kim SH, et al. Usefulness of a direct $16 \mathrm{~S}$ rRNA gene PCR assay of percutaneous biopsies or aspirates for etiological diagnosis of vertebral osteomyelitis. Diagn Microbiol Infect Dis 78: 75-78, 2014.

18. Fenollar F, Roux V, Stein A, Drancourt M, Raoult D. Analysis of 525 samples to determine the usefulness of PCR amplification and sequencing of the 16S rRNA gene for diagnosis of bone and joint infections. J Clin Microbiol 44: 1018-1028, 2006.

19. Fuursted K, Arpi M, Lindblad BE, Pedersen LN. Broad-range PCR as a supplement to culture for detection of bacterial pathogens in patients with a clinically diagnosed spinal infection. Scand J Infect Dis 40: 772-777, 2008.

20. Lecouvet F, Irenge L, Vandercam B, Nzeusseu A, Hamels S, Gala JL. The etiologic diagnosis of infectious discitis is improved by amplification-based DNA analysis. Arthritis Rheum 50: 29852994, 2004.

21. Campanilho-Marques R, Novelli V, Brogan PA, Eleftheriou D. Polyarticular septicarthritis in an 11-year-old child. Clin Rheumatol 33: 1181-1182, 2014.

22. Welkerling H, Geissdörfer W, Aigner T, Forst R. Osteomyelitis of the ulna caused by Porphyromonas gingivalis. J Clin Microbiol 44: 3835-3837, 2006.

23. Harris KA, Fidler KJ, Hartley JC, et al. Unique case of Helicobacter sp. osteomyelitis in an immunocompetent child diagnosed by broad-range 16S PCR. J Clin Microbiol 40: 3100-3103, 2002.

24. La Scola B, Michel G, Raoult D. Use of amplification and sequencing of the 16S rRNA gene to diagnose Mycoplasma pneumoniae osteomyelitis in a patient with hypogammaglobulinemia. Clin Infect Dis 24: 1161-1163, 1997.

25. Sanchez MC, Sebti R, Hassoun P, et al. Osteomyelitis of the patella caused by Legionella anisa. J Clin Microbiol 51: 2791-2793, 2013.

(C) 2015 The Japanese Society of Internal Medicine http://www.naika.or.jp/imonline/index.html 